\title{
Destinação de riqueza aos empregados no Brasil: comparação entre empresas estatais e privadas do setor elétrico (2004-2007)
}

\section{Destination of wealth for employees in Brazil: comparison between state and private companies in the electric sector (2004-2007)}

\author{
Esmael Almeida Machado \\ Professor Assistente do Curso de Ciências Contábeis na Unidade Universitária de Ponta Porã - MS da Universidade Estadual de Mato Grosso do \\ Sul e Egresso (2007-2008) do Programa de Pós-Graduação (Mestrado) em Contabilidade da Universidade Federal do Paraná \\ -E-mail: esmael@uems.br \\ Rafael Borges Morch \\ Professor do Programa de Pós-Graduação em Ciências Contábeis da Faculdade de Administração e Ciências Contábeis da Universidade Federal \\ do Rio de Janeiro • E-mail: rafael.morch@gmail.com \\ Dilo Sergio de Carvalho Vianna \\ Professor Substituto do Departamento de Administração da Faculdade de Administração e Ciências Contábeis da Universidade Federal do Rio \\ de Janeiro・E-mail: diloscv@hotmail.com \\ Ruthberg dos Santos \\ 'Professor Adjunto do Programa de Mestrado em Ciências Contábeis da Faculdade de Administração e Ciências Contábeis da Universidade \\ Federal do Rio de Janeiro•E-mail: ruthberg@facc.ufrj.br
}

José Ricardo Maia de Siqueira

Professor Adjunto do Programa de Mestrado em Ciências Contábeis da Faculdade de Administração e Ciências Contábeis da Universidade Federal do Rio de Janeiro • E-mail: jrms@facc.ufrj.br

* Os autores agradecem ao apoio da Capes.

*Artigo apresentado no $3^{\circ}$ EnAPG, Salvador-BA, 2008.

Recebido em 24.02.2009 - Aceito em 20.05.2009 • $2^{a}$ versão aceita em 08.07:2009

\section{RESUMO}

Diversos estudos comparam empresas estatais e privadas ou os efeitos da privatização, em que são debatidos temas como eficiência econômica e o papel social das empresas. Muitas pesquisas indicam que as empresas estatais são menos eficientes economicamente, devido à responsabilidade social desenvolvida por elas (distribuição de renda). Tendo como base essas informações, este trabalho tem como objetivo verificar se existem diferenças significativas entre empresas estatais e privadas do setor elétrico brasileiro, relacionadas à distribuição da riqueża gerada aos empregados, a partir de dados coletados da Demonstração de Valor Adicionado e do Balanço Social, para o período de 2004 a 2007. Primeiramente, foi verificado se há diferença na percentagem da distribuição da riqueza gerada para os empregados. Em seguida, foi examinado se há diferença no número de funcionários entre empresas privadas e estatais. Por último, foi conferido se há diferença na remuneração média per capita. Para a realização desses propósitos foi utilizado o teste estatístico não paramétrico Mann-Withney. Os testes indicam que as empresas estatais gastam mais com funcionários do que as privadas e que a origem dessas diferenças se encontra na quantidade de funcionários, sendo que a partir de 2006, adicionalmente, em função de maiores remunerações.

Palavras-chave: Setor elétrico. Distribuição da riqueza. Demonstração do valor adicionado. 


\section{ABSTRACT}

Several studies compare the effects of privatization in state and private companies, where they discuss issues like economic efficiency and the social role of business. Many indicate that state enterprises are less efficient economically, but that they develop social responsibilities, including the distribution of income. Based on this information, this study aims to determine if there are significant differences among state and private enterprises in the electric sector, related to the distribution of wealth generated to employees. Data were collected from the Statement of Cash Flows and the Social Balance Sheet, for the period from 2004 to 2007. First, it was examined whether there was any difference in the percentage of the distribution of wealth generated for the employees. Then, it was checked if there was any difference in the number of employees from private and state companies. Finally, it was verified if there was any difference in average pay per capita. To examine this connection, Mann-Whitney's non-parametric test was used. The tests indicate that companies spend more on state officials than on private employees and that the origin of these differences is the amount of staff in 2006 and, additionally, higher earnings.

Keywords: Energy sector. Distribution of wealth. Statements of cash flows.

\section{INTRODUÇÃO}

A empresa é um agente econômico que integra a sociedade em que atua e, por esse motivo, debate-se seu papel no ambiente social. Para tal discussão, há ao menos duas vertentes para o assunto: i) as empresas não devem assumir qualquer responsabilidade social além de dar lucro aos seus proprietários e ii) as empresas, como os demais integrantes da sociedade, possuem uma relação endógena que impossibilita afirmar sobre a independência dos agentes envolvidos; não respaldando, portanto, deveres da empresa apenas com seus proprietários (CERTO; PETER, 1993; WRIGHT; KROLL; PARNELL, 2000).

Desde o governo Fernando Collor (19901992), muitas empresas estatais foram privatizadas com a alegação de que não era papel do Estado administrá-las. Somado a isso, sempre se questionou sobre a eficiência e eficácia dessas empresas. O principal argumento para esse questionamento era: caso estivesse na iniciativa privada, elas apresentariam melhores resultados econômicos.

O referido argumento foi tema de propaganda do governo Collor, que caracterizava as empresas estatais como deficitárias, responsabilizando-as de onerar o Estado. O plano do Governo era vender as empresas e, com os recursos, investir na área social. Contexto parecido foi utilizado no governo do Presidente Fernando Henrique (1995-2002) para a privatização da Companhia Vale do Rio Doce, no qual se dizia que a privatização simplesmente objetivava tirar do Estado atividades que estariam mais bem geridas pela iniciativa privada (MATOS, 2001).

A respeito das privatizações, os debates são controversos em relação a uma maior eficiência das empresas com controle acionário privado. Biondi (1999) relata que a ineficiência do Estado em gerir empresas está relacionada a questões sociais. $\mathrm{O}$ autor afirma que o governante, não foca a exploração econômica das empresas, mas, sim, as utiliza para o exercício de políticas sociais.

Considerando esse último propósito mencionado, há pesquisas (POCHMANN, 2001; CASTELAR, 2001) que defendem os dois lados, tanto a privatização quanto a permanência das empresas estatais nas mãos do Governo. Pochmann (2001) informa que, entre 1990 e 1999, mais de 500 mil vagas de empregos deixaram de existir em empresas privatizadas. Por outro lado, Castelar (2001) diz que o investimento decorrente da desestatização criou novas oportunidades de trabalho, compensando os efeitos da privatização, ou seja, a 
médio prazo não há uma diminuição de postos de trabalho.

Tendo como base a discussão sobre os aspectos sociais das atividades empresariais, este trabalho tem o objetivo de verificar se existem diferenças significativas entre empresas estatais e privadas do setor elétrico, relacionadas à distribuição da riqueza gerada aos empregados, a partir de dados coletados da Demonstração de Valor Adicionado e do Balanço Social. A análise restringe-se ao setor de energia elétrica para o período compreendido entre 2004 e 2007.

Para atingir tal objetivo, o estudo pautouse em pesquisa bibliográfica e abordagem empírico-analítica, com a utilização de técnicas de coleta, tratamento e análise de dados quantitativos (MARTINS, 2001). A amostra analisada abrange empresas de energia elétrica brasileiras, que divulgaram suas demonstrações contábeis no período de 2004 a 2007. As variáveis da pesquisa foram: a riqueza gerada, a distribuição de riqueza aos empregados e a quantidade de funcionários. Para tratamento estatístico dos dados, trabalhou-se com a metodologia de dados não paramétricos.
Justifica-se a análise proposta pela existência de empresas estatais e privadas atuando na geração, transmissão e distribuição de energia elétrica, assim como, das empresas privadas hoje, muitas delas passaram pelo processo de privatização iniciado na década de 1990, que rendeu aos Governos Federal e Estadual, US\$ 31,7 bilhões (BNDES, 2008). Outro aspecto importante é a sua representatividade econômica, que corresponde a 5,5\% do PIB apurado no primeiro trimestre de 2008 (FURNAS, 2008).

A presente pesquisa está estruturada em seis seções, a saber: a introdução ora apresentada; o referencial teórico que compreende: diferenças entre empresas com controle acionário estatal e privado e as finalidades do Balanço Social e da Demonstração do Valor Adicionado (DVA). A seguir, são detalhados os procedimentos metodológicos, seguido das análises e discussões dos dados coletados. Por fim, na última seção, são expostas as considerações finais.

\section{ASPECTOS ACERCA DO CONTROLE ACIONÁRIO (ESTATAL $\times$ PRIVADO): CONTRIBUIÇÃO DA EMPRESA À SOCIEDADE}

No ambiente de discussões do campo teórico e do senso comum, as empresas com controle acionário estatal são percebidas como tendo menor eficiência em termos de gestão econômico-financeira (PINHEIRO; GIAMBIAGI, 2004; WERNECK, 1989; CHAIN; SILVA; MARTINS, 2007). Isso porque, atuando em ambiente de competição com igualdade de condições, as empresas com controle acionário privado apresentam desempenho operacional e/ou financeiro superior, consequentemente, são mais rentáveis em termos econômicos, conforme constataram Boardman e Vining (1989), Barbosa (1997) e Oliveira e Lustosa (2005), que, em seus estudos, comparam os dados econômicos financeiros de empresas antes e após o processo de privatização.

A esse respeito Neto (2002) afirma que as privatizações são justificadas pela busca de uma maior competitividade e eficiência devido à incapacidade do poder público de administrar as empresas em seu poder acionário. Três fatores reforçam essa argumentação e ajudam a compreender tal incapacidade, conforme justifica Pinheiro (1996): i) o conflito entre objetivos políticos e comerciais; ii) os objetivos políticos pessoais dos dirigentes ou daqueles que o colocaram nessa posição e iii) o apoio financeiro do Estado.

$\mathrm{O}$ primeiro fator refere-se aos interesses políticos de uma organização, que são con- 
flitantes com a maximização dos resultados, devido à existência de sacrifícios financeiros no alcance de objetivos sociais. Os interesses políticos estão relacionados com o "desenvolvimento de setores dentro da cadeia produtiva, integração do território nacional, o atendimento a populações carentes, o nível de emprego, o controle da inflação, etc" (PINHEIRO, 1996, p. 32). Os interesses comerciais das empresas visam a uma maior rentabilidade na venda de seus produtos e serviços, objetivando o lucro.

Os cargos de diretoria são, muitas vezes, escolhidos por questões políticas do Governo em vigência e, por consequência, os objetivos não econômicos acabam influenciando as decisões das organizações, fazendo com que o lucro não seja prioridade dos gestores da empresa.

O terceiro fator diz respeito ao menor risco de uma empresa estatal falir pois elas possuem maior facilidade ao acesso de recursos, principalmente advindos do Estado, direta ou indiretamente. $\mathrm{O}$ conhecimento dessa realidade faz com que gerentes e funcionários negligenciem a pressão de obter lucro e operar mais eficientemente (PINHEIRO 1996).

Os argumentos apresentados são corroborados pela teoria da agência, para a qual o relacionamento de agência é definido como "um contrato no qual uma ou mais pessoas - o principal - engajam outra pessoa - o agente para desempenhar alguma tarefa em seu favor, envolvendo a delegação de autoridade para a tomada de decisão pelo agente" (JENSEN; MECKLING, 1976, p. 310). A partir dessa teoria, os autores explicam como estruturas distintas de propriedade, afetam a conduta dos empregados e da administração das companhias, de acordo com seu controle acionário.

Entretanto, caso uma empresa estatal fosse considerada eficiente, ela dificilmente sofreria privatização, pois isso, provavelmente, pioraria o resultado das contas públicas, devido à retirada das necessidades de financiamento dessa empresa do cálculo do déficit público.
Esta é uma situação que seria positiva para o Estado, caso houvesse um pagamento de ágio compensatório (GIAMBIAGI; ALEM, 1999).

Uma pesquisa da Revista EXAME (2008), realizada em março de 2005, questiona dois grupos - empresários e população em geral e pergunta: qual a missão das empresas? Mesmo não sendo uma pesquisa acadêmica, seu resultado mostra uma interessante diferença de percepção entre esses dois grupos. O lucro aparece em primeiro lugar para os empresários, com $82 \%$, enquanto para a população aparece em oitavo com 10\%. Entretanto, em primeiro lugar para a população em geral, aparece a geração de emprego com 93\%, que, para os empresários, se torna a quinta opção com 34\%. Assim, constata-se a preocupação da população com a questão social, o que tem ressonância na gestão estatal de empresas, visualizando os interesses conflitantes entre o social e o comercial.

Pinheiro (1996) avalia empresas brasileiras, analisando a sua performance quanto a modificações após a alteração do controle acionário (de estatal para privado). A pesquisa revela que, entre outras alterações, houve uma redução do trabalho assalariado, porém, se a empresa começa a aumentar a suas vendas, as contratações de empregados podem ser feitas para atender essa demanda, principalmente, se há um aumento nos investimentos; sendo essa uma outra informação encontrada pelo autor.

Karamanis (2009) ressalta que, com a privatização, há uma melhoria em eficiência significativa nos países desenvolvidos. Nos países subdesenvolvidos, o sistema de privatização apresenta falhas, pois os mercados de capitais apresentam fraca regulamentação, além do fato de o setor público constituir a maior parte do PIB. Nesses países, também, faltam ingredientes básicos para o êxito de uma privatização, como: executivos capacitados, empresários e fontes de capital.

$\mathrm{Na}$ conclusão de seu estudo, Karamanis (2009) relata que, em geral, a privatização das empresas de telecomunicações conduziu essas 
organizações a um significativo aumento no desempenho. As empresas estatais são menos eficientes e isso ocorre, possivelmente, devido à pressão política. A gerência não exerce controle orçamentário, assim como sobre os níveis salariais ou políticas para a obtenção de receitas sem a aprovação do Estado, o que diminui a capacidade da empresa em satisfazer as demandas dos clientes e manter o ritmo com a rápida mudança tecnológica. Além disso, as empresas públicas não visam à maximização de lucros, optando por objetivos sociais e políticos, tais como a redistribuição da riqueza.

O governo tem um forte incentivo para desviar-se da maximização do lucro para atingir os seus próprios objetivos, tais como: geração de empregos, equilíbrio de entradas e saídas de mercadorias, de promoção comercial, de estabilização política e econômica etc., repassando esses custos para as empresas estatais (CHEN, 2000).

Opinião parecida têm Debrah e Toroitich (2005) quando afirmam que o problema de uma empresa estatal, mais precisamente a Kenya Airways, são a falta de profissionalismo e a capacidade dos gestores. Os autores concluem seu estudo relatando que a privatização da empresa fez bem ao Quênia.

Boarding e Vining (1989) compararam 499 empresas de capital estatal e privado, estabelecidas fora dos Estados Unidos, e observaram diferenças no desempenho econômico das companhias em função do seu controle acionário. Os autores concluíram que as companhias nas quais o Estado exerce a função de controlador, o desempenho econômico é inferior àquelas em que a iniciativa privada detém o controle.

Em termos da distribuição da riqueza
Chan, Silva e Martins (2007) utilizaram a DVA em sua pesquisa. Os autores verificaram que empresas estatais destinam maior parcela da riqueza gerada aos seus funcionários em relação às empresas privadas, sem, entretanto, discutirem o motivo dessa diferença. Supõe-se que essa parcela maior pode ocorrer por dois motivos: i) remuneração, direta e indireta, maior ou ii) quantidade maior de funcionários. Para Baer (2003), os dois motivos justificam esses gastos superiores das estatais.

Tão importante quanto as diferenças nos gastos com empregados, está a relação de satisfação dos funcionários em seu ambiente profissional. Levando em consideração esse aspecto, Wang (2008) comparou empresas privadas e estatais chinesas aplicando questionários aos seus funcionários. Diferentemente do que esperava, verificou que os funcionários das empresas privadas estão mais satisfeitos com seus empregos do que os funcionários das empresas estatais. Wang (2008) justifica o ocorrido pelo fato de as empresas privadas proporcionarem mais desafios a seus funcionários, fazendo com que eles tenham maior reconhecimento pelos objetivos alcançados. Além disso, foi mencionado que as empresas privadas possuem uma "atmosfera" mais harmoniosa.

Relacionado a um melhor ambiente de trabalho, está o fato de que os empregados de empresas privadas possuem uma relação emocional maior com os objetivos da empresa. Isso não acontece tão intensamente por parte dos empregados das empresas estatais, porque eles possuem menos confiança em seus superiores, provocada pela falta de transparência nos meios de comunicação interna (WANG, 2008).

\section{BALANÇO SOCIAL (BS) E DEMONSTRAÇÃO DO VALOR ADICIONADO (DVA)}

Uma das mais citadas definições de responsabilidade social é proposta por Carroll (1979). O autor afirma que as empresas que praticam a responsabilidade social devem atender as expectativas econômicas, jurídicas, éticas e discricionárias (filantrópicas) que 
a sociedade tem em relação às organizações em um determinado período de tempo. Claramente, Carroll (1979) assume a perspectiva de que as empresas são responsáveis para a sociedade e devem fazer o que se espera delas. Para as empresas preocupadas somente com o lucro, isto implicaria numa mudança cultural na organização e, também, uma inevitável reavaliação das metas corporativas (TREBECK, 2008).

Contrapondo a esse pensamento, Clarkson (1995) considera que as empresas não são responsáveis perante a sociedade, porém são responsáveis perante seus stakeholders e veem a responsabilidade a partir dessa perspectiva.

Por conta de pressões da sociedade em geral, as empresas mobilizaram-se para se apresentarem, socialmente, responsáveis. Nesse contexto surgiram os relatórios sociais, instrumentos que têm o objetivo potencial de evidenciar o impacto das atividades corporativas na sociedade.

Deegan, Rankin, Voght (2000) informam que há uma série de estudos que mostram que os investidores estão atentos às divulgações de caráter social. Levantamentos com base em investigação, também, confirmam que vários grupos de stakeholders estão interessados em encontrar divulgações sociais que sejam úteis aos seus processos decisórios.

Relatórios de sustentabilidade corporativa, geralmente, são elaborados com base nos critérios estabelecidos por um formato determinado por algum tipo de entidade. Isenmann, Bey e Welter (2007) consideram que suas raízes estão na inter-relação de três pilares: ambiental, social e desempenho econômico.

O Balanço Social (BS) é o instrumento de evidenciação das políticas e investimentos sociais de uma organização. Sucupira (2008, p. 1) define-o como "um documento publicado anualmente, reunindo um conjunto de informações sobre atividades desenvolvidas por uma empresa, em promoção humana e social, dirigidas a seus empregados e a comunidade na qual está inserida”. A intenção é que o BS seja um instrumento não tendencioso, visando à mensuração do impacto social de uma organização. Esse conceito carrega dentro de si uma inverdade ao deixar subentendido que essa demonstração objetiva a divulgação de sua atuação em benefício da sociedade (RIOLI, 1997).

Souza (1997) conceitua BS, afirmando que se trata "de uma avaliação para medir e julgar os fatos sociais vinculados à empresa, tanto internamente (empresa/empregados) como externamente (empresa/comunidades)". É uma definição simples e não preconiza o viés de marketing social encontrado em outros conceitos (PEROTTONI; CUNHA, 1997; ARRIGONI, 2000; SUCUPIRA, 2008).

$\mathrm{O}$ primeiro país que regulamentou a publicação do BS foi a França, por meio da Lei $\mathrm{n}^{\circ} 77.769$, de 12 de julho de 1977, sendo esse exemplo seguido por Portugal, em 1985, e, posteriormente, pela Bélgica, em 1996 (TINOCO, 2001).

Segundo Iudícibus, Martins e Gelbcke (2003), o BS possui quatro vertentes: o Balanço Ambiental, o Balanço de Recursos Humanos, a Demonstração do Valor Adicionado e os Benefícios e Contribuições à Sociedade em geral. Alguns dos modelos de BS utilizados, atualmente, pelas empresas - como, por exemplo, o modelo do Instituto Brasileiro de Análises Sociais e Econômicas (Ibase) - contemplam, em maior ou menor grau, todas as vertentes.

A agência reguladora do setor elétrico brasileiro, Agência Nacional de Energia Elétrica (ANEEL), torna obrigatória a elaboração e publicação do BS e da DVA nesse segmento de mercado. A ANEEL cria essa obrigatoriedade por meio da Resolução Normativa $n^{\circ}$. 444/2001 (ANEEL, 2008a), concomitante com a publicação do Manual de Contabilidade do Serviço Público de Energia Elétrica (MCSPE). O manual - MCSPE - sugere como parâmetro para a elaboração do BS o modelo do Ibase (ANEEL, 2008b).

O modelo de BS publicado pelo Ibase é dividido em sete conjuntos de indicadores 
apresentados separadamente: (1) a base de cálculo; (2) os indicadores sociais internos; (3) os indicadores sociais externos; (4) os indicadores de meio ambiente; (5) os indicadores de corpo funcional; (6) os índices de cidadania empresarial, como, por exemplo, a relação com consumidores e encerra com uma "abertura" para (7) outras informações.

A DVA mostra a parcela do resultado que é destinada aos investidores, bem como apresenta, em detalhes, de que maneira a riqueza criada é distribuída à sociedade (DE LUCA, 1998). A principal característica da DVA é a evidenciação do valor da riqueza gerada pela empresa e sua distribuição aos stakeholders (empregados, Governo, financiadores e acionistas). Na percepção de Consenza (2003), a DVA permite visualizar a realidade empresarial sob dois enfoques: a) o econômico, relativo ao valor gerado; b) o social, correspondente às rendas distribuídas. Dessa maneira, tanto os acionistas têm seus interesses atendidos quanto os demais stakeholders.

O Reino Unido foi o primeiro país a elaborar a DVA, largamente utilizada no período de recuperação econômica do pós-guerra, justamente por evidenciar a participação dos empregados. Dessa forma, foi utilizada como um instrumento para a administração do desempenho econômico de empresas da época (BURCHEL; CLUBB; HOPWOOD, 1985).

Os dados para elaboração da DVA são extraídos da contabilidade, sobretudo da Demonstração do Resultado do Exercício (DRE), sem que se faça, entretanto, confusão entre a fi- nalidade de ambas, tendo em vista que o maior propósito da DRE consiste em comunicar a composição dos resultados da empresa aos usuários da contabilidade (SANTOS, 2003).

No Brasil, a partir de 2009 (referentes aos exercícios de 2008 e 2007) todas as empresas com ações e títulos negociados em bolsa de valores no Brasil devem elaborar e divulgar a DVA, conforme a Lei 11.638/07. Diante disso, o Comitê de Pronunciamentos Contábeis (CPC) elaborou o CPC 09, que trata do modo de elaboração dessa demonstração. Um dos pontos abordados pelo CPC para a importância da DVA refere-se:

Para os investidores e outros usuários, essa é uma demonstração que proporciona o conhecimento de informações de natureza econômica e social e oferece a possibilidade de uma melhor avaliação das atividades da entidade dentro da sociedade que a abriga. A decisão de recebimento por uma comunidade (Município, Estado e a própria Federação) de um investimento poderá ter nessa demonstração um instrumento de extrema utilidade e com informações que, por exemplo, a demonstração de resultados por si só não é capaz de oferecer (CPC 09, 2008, p. 4).

Em termos gerais, o CPC explicita, nesse pronunciamento, que a informação originada na DVA estará presente na análise para decisões de investimento e financiamento, considerando que o impacto da empresa na sociedade em termos monetários, fica evidenciado de maneira ímpar nessa demonstração.

\section{PROCEDIMENTOS METODOLÓGICOS}

Com a finalidade de verificar as diferenças entre empresas estatais e privadas em relação aos gastos com empregados, informação essa constante das demonstrações BS e DVA, optou-se pela realização de uma pesquisa com empresas brasileiras do setor de energia elétrica, devido à sua relevância econômica, bem como à exigência imposta pela Resolução 444/2001 da ANEEL.

\subsection{Caracterização da amostra}

Identificaram-se as companhias do setor elétrico que publicaram suas demonstrações financeiras entre o período de 2004 a 2007, a 
partir de uma relação de empresas do setor, divulgada no site do Operador Nacional do Sistema Elétrico (ONS). Definidos quais dados seriam coletados, procedeu-se à sua coleta a partir de várias fontes, notadamente, em jornais do meio econômico, site da Comissão de Valores Mobiliários e dos sites das próprias companhias. O período de coleta de dados correspondeu aos meses de abril a junho de 2008 e foram excluídas aquelas empresas que não publicaram o Balanço Social e a DVA.

A amostra foi segregada em dois grupos, conforme o controle acionário: a) empresas estatais; b) empresas privadas. A amostra para análise ficou composta conforme detalhamento da Tabela $1 \boldsymbol{\nabla}$.

Pela utilização do BOXPLOT - ferramenta estatística disponibilizada no software SPSS - foi verificada a ocorrência de outliers na distribuição de riquezas aos empregados. Nesse caso, os outliers, por representarem possibilidade de interpretações equivocadas, foram excluídos.

\subsection{Técnicas estatísticas utilizadas para análise dos dados}

Os dados foram analisados com a aplicação do teste Mann-Whitney, com nível de significância de 5\%. Quando o p-value for superior ao nível de significância préestabelecido, o resultado indica que a hipótese nula de igualdade de médias não pode ser rejeitada e, se for inferior, não deve ser aceita. Trata-se de um teste não paramétrico destinado a verificar se duas amostras independentes provêm de populações com médias iguais, em nível de significância préestabelecido. $\mathrm{O}$

Tabela 1 Composição da amostra em análise

\begin{tabular}{l|c|c|c|c|c}
\hline № de empresas & $\mathbf{2 0 0 4}$ & $\mathbf{2 0 0 5}$ & $\mathbf{2 0 0 6}$ & $\mathbf{2 0 0 7}$ & Total \\
\hline Privadas & 29 & 31 & 30 & 34 & 124 \\
\hline Públicas & 16 & 18 & 20 & 20 & 74 \\
\hline Total & 45 & 49 & 50 & 54 & 198 \\
\hline
\end{tabular}

teste consiste na atribuição de postos às observações, como se essas fizessem parte de uma única amostra. Se a hipótese nula for verdadeira, os postos baixos, médios e altos estarão distribuídos, equilibradamente, entre as duas amostras. Foi verificada se a participação dos Empregados é ou não diferente entre os grupos de empresas em termos de: i) proporção do valor adicionado que foi destinado a gastos com Empregados no período; ii) valor adicionado total per capita de empregados; iii) valor adicionado distribuído a empregados per capita.

Adotaram-se essas variáveis, pois, conforme Boyko, Shleifer e Vishny (1996), o excesso de mão de obra, frequentemente, é observado como causa da suposta ineficiência das empresas estatais. Nesse sentido, pela realização do teste de Manny-Wyitney, buscam-se inferências em relação a eventuais dessemelhanças no valor médio da riqueza gerada e distribuída aos empregados no período de 2004 a 2007 entre as empresas brasileiras de energia elétrica.

Com a utilização do teste Kruskal-Wallis, comparou-se para cada grupo de empresas, a média anual do percentual de Valor Adicionado Distribuído a Empregados (variável) ao longo dos quatro anos da série em análise, a fim de testar se permaneceu sem mudança significativa durante o período analisado. De acordo com Martins (2001, p. 280), o teste de Kruskal-Wallis é útil para identificar "se $\mathrm{K}$ amostras $(\mathrm{K}>2)$ independentes provêm de populações com médias iguais". O referido teste indica em termos estatísticos, se, no período analisado, não houve alteração significativa no percentual de riqueza destinado aos empregados entre os dois grupos, tanto empresas estatais como empresas privadas. 


\section{ANÁLISE DOS RESULTADOS}

Os resultados da aplicação do teste de Mann-Whitney, que investiga o comportamento do percentual médio de riqueza distribuída aos empregados, por empresas estatais e empresas privadas, são apresentados na Tabela $2 \boldsymbol{\nabla}$. Se $p$-value for superior ao nível de significância préestabelecido, no caso 5\%, o resultado do teste sugere que a hipótese nula de igualdade de médias não pode ser rejeitada e, se for inferior, não deve ser aceita.

Observe-se, na Tabela 2, que, para o período analisado, o $p$-value referente ao percentual do valor adicionado que foi distribuído aos empregados, é menor que o nível de significância de 5\%. Nesse caso, considera-se a rejeição da hipótese de igualdade de médias entre empresas estatais e privadas. Pode-se inferir quanto a indícios que, em média, a participação dos empregados na distribuição de riqueza é maior nas estatais tendo em vista que, na média dos postos, as empresas estatais estiveram à frente das empresas privadas, sem apresentar nenhuma variação significativa. Esse resultado está em conformidade ao encontrado por Chan, Silva e Martins (2007).

Tabela 2

Resultado de Mann-Witney para remuneração por empregado

\begin{tabular}{|c|c|c|c|c|}
\hline \multirow{2}{*}{\multicolumn{3}{|c|}{$\begin{array}{l}\text { H0: } \mu \text { privada }=\mu \text { pública } \\
\text { H1: } \mu \text { privada }<\mu \text { pública }\end{array}$}} & \multicolumn{2}{|c|}{ Empresa } \\
\hline & & & \multirow{2}{*}{$\frac{\text { Privada }}{34}$} & \multirow{2}{*}{$\frac{\text { Estatal }}{20}$} \\
\hline \multirow{12}{*}{ 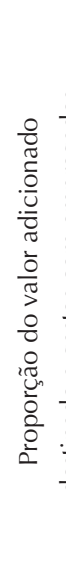 } & \multirow{3}{*}{2007} & $n$ & & \\
\hline & & Média dos postos & 21,23 & 38,15 \\
\hline & & $p$-value (bi-caudal) & \multicolumn{2}{|c|}{0,0001} \\
\hline & \multirow{3}{*}{2006} & $n$ & 30 & 20 \\
\hline & & Média dos postos & 19,64 & 35,85 \\
\hline & & $p$-value (bi-caudal) & \multicolumn{2}{|c|}{0,0001} \\
\hline & \multirow{3}{*}{2005} & $n$ & 31 & 18 \\
\hline & & Média dos postos & 18,27 & 36,58 \\
\hline & & $p$-value (bi-caudal) & \multicolumn{2}{|c|}{0,0000} \\
\hline & \multirow{3}{*}{2004} & $n$ & 29 & 16 \\
\hline & & Média dos postos & 18,94 & 30,34 \\
\hline & & $p$-value (bi-caudal) & \multicolumn{2}{|c|}{0,0053} \\
\hline
\end{tabular}

Entretanto, tal fato pode ter relação com o número de empregados vinculados a cada grupo de empresas, não permitindo identificar se as diferenças percebidas entre as percentagens de valor adicionado distribuídas aos funcionários se devem a: (a) uma maior remuneração por empregado ou (b) a um maior número de funcionários nas estatais.

O resultado da primeira análise indica, apenas, que, nas empresas estatais, a proporção da riqueza distribuída aos empregados foi maior em relação à riqueza total gerada. Nesse sentido, reporte-se, mais uma vez, ao argumento apresentado por Pinheiro (1996) a respeito das motivações para a ineficiência percebida em empresas públicas e que motivaram as privatizações. $\mathrm{O}$ autor indica que, por conta do apoio financeiro do Estado e da divergência presente entre os objetivos políticos dos dirigentes em relação aos interesses da empresa, os gestores das empresas estatais atentam menos para a minimização de custos ou maximização de lucro.

A Tabela 30 apresenta os resultados da aplicação do teste de Mann-Whitney, que in-

Tabela 3 Resultado de Mann-Witney para renda per capita

\begin{tabular}{|c|c|c|c|c|}
\hline \multirow{2}{*}{\multicolumn{3}{|c|}{$\begin{array}{l}\text { H0: } \mu \text { privada }=\mu \text { pública } \\
\text { H1: } \mu \text { privada }>\mu \text { pública }\end{array}$}} & \multicolumn{2}{|c|}{ Empresa } \\
\hline & & & \multirow{2}{*}{$\frac{\text { Privada }}{34}$} & \multirow{2}{*}{$\begin{array}{c}\text { Estatal } \\
20\end{array}$} \\
\hline \multirow{12}{*}{ 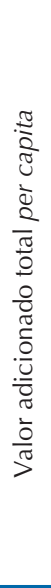 } & \multirow{3}{*}{2007} & $\mathrm{n}$ & & \\
\hline & & Média dos postos & 32,91 & 20,04 \\
\hline & & $p$-value (bi-caudal) & \multicolumn{2}{|c|}{0,0038} \\
\hline & \multirow{3}{*}{2006} & $n$ & 30 & 20 \\
\hline & & Média dos postos & 30,16 & 19,55 \\
\hline & & $p$-value (bi-caudal) & \multicolumn{2}{|c|}{0,128} \\
\hline & \multirow{3}{*}{2005} & $\mathrm{n}$ & 31 & 18 \\
\hline & & Média dos postos & 28,35 & 19,22 \\
\hline & & $p$-value (bi-caudal) & \multicolumn{2}{|c|}{0,0310} \\
\hline & \multirow{3}{*}{2004} & $\mathrm{n}$ & 29 & 16 \\
\hline & & Média dos postos & 25,62 & 18,25 \\
\hline & & $p$-value (bi-caudal) & \multicolumn{2}{|c|}{0,0715} \\
\hline
\end{tabular}


vestiga o comportamento do valor adicionado total per capita de empregados, também segregados por tipo de controle acionário (privadas e estatais). Para determinação dessa variável (valor adicionado per capita) levouse em conta o resultado da divisão entre o total de valor adicionado gerado nas respectivas empresas e o número de empregados segundo o Balanço Social divulgado. Se p-value for superior ao nível de significância préestabelecido, no caso $5 \%$, o resultado do teste sugere que a hipótese nula de igualdade de médias não pode ser rejeitada e, se for inferior, não deve ser aceita. O teste foi realizado a partir do cálculo da renda per capita dos empregados em função do Valor Adicionado total de cada empresa, identificando o valor da riqueza total da empresa por empregado. Dessa maneira, esperava-se padronizar o valor da riqueza gerada, em que o padrão de referência é o empregado.

Os dados apresentados, na Tabela 3, revelam que, para o período analisado, o $p$-value referente ao percentual do valor adicionado distribuído aos empregados é menor que o nível de significância de $5 \%$, exceto para o ano de 2004 que apresentou $p$-value de 7,1\%. Nesse caso, considera-se a rejeição da hipótese de igualdade de médias entre empresas privadas e estatais, exceto para o ano de 2004. Para esse ano não é possível deduzir sobre diferença entre as médias.

Para o período de 2005 a 2007, é possível inferir que há indícios que, em média, a riqueza gerada pelas empresas privadas é maior, considerando a padronização em termos de renda per capita de empregados, tendo em vista que, na média dos postos, as empresas privadas estiveram à frente das empresas estatais. Em outras palavras, as estatais possuem um contingente maior de funcionários para uma geração de riqueza proporcional à das privadas.

A Tabela 4 mostra os resultados obtidos para a distribuição da riqueza gerada para os empregados, buscando identificar se existem diferenças significativas entre as remunerações recebidas pelos funcionários entre o grupo de empresas públicas e o das empresas privadas.

Percebe-se, na Tabela $4 \mathbf{\nabla}$, uma evolução na média dos postos em ambos os grupos de empresas. Entretanto, nas empresas estatais, esse aumento foi mais representativo, saindo de 26,43 em 2004 para 34,45 em 2007. Em função desse aumento na média dos postos a partir de 2006, fica evidenciada uma diferença entre o valor adicionado padronizado em termos de renda per capita distribuído aos empregados, havendo indícios de aumento nos salários médios por empregado.

O resultado do teste de Kruskal-Wallis para distribuição da riqueza gerada para os empregados é apresentado na Tabela 50 .

Com base nos resultados do teste de Kruskal-Wallis (Tabela 5), verifica-se que, ao longo do período analisado, o percentual da riqueza gerada destinada aos empregados não apresentou diferença, estatisticamente, significativa, tanto nas empresas privadas quanto nas empresas estatais, em nível de significância préestabelecido.

Tabela 4 Resultado de Mann-Witney para distribuição da riqueza gerada para os empregados

\begin{tabular}{|c|c|c|c|c|c|}
\hline \multirow{2}{*}{\multicolumn{4}{|c|}{$\begin{array}{l}\text { H0: } \mu \text { privada }=\mu \text { pública } \\
\text { H1: } \mu \text { privada }<\mu \text { pública }\end{array}$}} & \multicolumn{2}{|c|}{ Empresa } \\
\hline & & & & Privada & Estatal \\
\hline \multirow{12}{*}{ 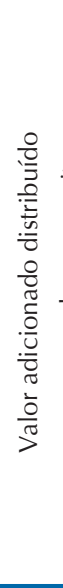 } & \multirow{12}{*}{ 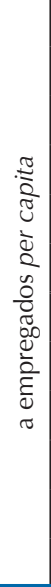 } & \multirow{3}{*}{2007} & $n$ & 34 & 20 \\
\hline & & & Média dos postos & 23,41 & 34,45 \\
\hline & & & $p$-value (bi-caudal) & \multicolumn{2}{|c|}{0,0127} \\
\hline & & \multirow{3}{*}{2006} & $n$ & 30 & 20 \\
\hline & & & Média dos postos & 22,00 & 30,75 \\
\hline & & & $p$-value (bi-caudal) & \multicolumn{2}{|c|}{0,0375} \\
\hline & & \multirow{3}{*}{2005} & $n$ & 31 & 18 \\
\hline & & & Média dos postos & 22,12 & 29,94 \\
\hline & & & $p$-value (bi-caudal) & \multicolumn{2}{|c|}{0,0649} \\
\hline & & \multirow{3}{*}{2004} & $n$ & 29 & 16 \\
\hline & & & Média dos postos & 21,10 & 26,43 \\
\hline & & & $p$-value (bi-caudal) & \multicolumn{2}{|c|}{0,1921} \\
\hline
\end{tabular}


Tabela 5 Resultado de Kruskal-Wallispara distribuição da riqueza gerada para os empregados

\begin{tabular}{|c|c|c|c|c|c|c|c|}
\hline \multicolumn{2}{|c|}{$\begin{array}{l}\text { H0: } \mu 2007=\mu 2006=\mu 2005=\mu 2004 \\
\text { H1: Há ao menos uma diferença nas médias anuais }\end{array}$} & \multicolumn{3}{|c|}{ Empresas Privadas } & \multicolumn{3}{|c|}{ Empresas Estatais } \\
\hline Variável & Ano & $\mathbf{n}$ & $\begin{array}{l}\text { Média dos } \\
\text { postos }\end{array}$ & $p$-value & $\mathbf{n}$ & $\begin{array}{l}\text { Média dos } \\
\text { postos }\end{array}$ & $p$-value \\
\hline \multirow{4}{*}{$\begin{array}{l}\text { Percentual de valor adicionado } \\
\text { distribuído para empregados }\end{array}$} & 2007 & 34 & 65,74 & \multirow{4}{*}{0,9208} & 20 & 31,88 & \multirow{4}{*}{0,6190} \\
\hline & 2006 & 30 & 66,48 & & 20 & 36,11 & \\
\hline & 2005 & 31 & 60,73 & & 18 & 38,25 & \\
\hline & 2004 & 29 & 65,39 & & 16 & 41,05 & \\
\hline
\end{tabular}

\section{CONSIDERAÇÕES FINAIS}

O presente estudo objetivou apresentar as diferenças entre empresas estatais e privadas do setor de energia elétrica do Brasil, no período de 2004 a 2007 sob a ótica dos gastos com empregados, qual a origem das diferenças, ou seja, se é devido a salários mais altos ou devido a uma quantidade maior de funcionários.

Pôde-se constatar que o setor, em questão, apresentou diferença nos gastos com empregados no período analisado, em que as empresas estatais apresentam uma maior distribuição da riqueza aos funcionários do que as privadas, estatisticamente, discernível para todo o período.

Com relação ao valor adicionado per capi$\mathrm{ta}$, constatou-se, que no ano de 2004, o teste Mann-Witney não apresentou diferença significativa, mas que, por meio da informação da média dos postos, foram encontradas diferenças, sempre com o grupo das estatais com gastos superiores. Dessa forma, conclui-se que, no período de 2005 a 2007, as empresas estatais apresentaram, considerando-se a padronização, um maior número de funcionários em relação às privadas.

Quanto ao quesito: valor adicionado distribuído aos empregados per capita, o teste Mann-Witney revelou diferença significativa a partir do ano de 2006. Tal fato permite afirmar que os funcionários das empresas estatais receberam remuneração mais elevada do que seus congêneres das organizações privadas nos dois últimos anos do quadriênio analisado.

Os resultados apontados pela presente pesquisa indicam que as empresas estatais do setor elétrico brasileiro, distribuem uma maior parcela da riqueza gerada aos funcionários, corroborando os resultados apontados na pesquisa de Chan, Silva e Martins (2007). O teste Mann-Witney revela, adicionalmente, que a diferença na distribuição de riqueza aos funcionários se deve à manutenção de um maior número de funcionários nas estatais, confirmando, parcialmente, o que foi apontado por Baer (2003), que atribui tal diferença não só a uma maior quantidade de funcionários, mas, também, a uma maior remuneração recebida por esses. $\mathrm{Na}$ amostra analisada, só foi constatada diferenças significativas de remuneração, nos dois últimos anos do quadriênio.

Sob uma perspectiva econômico-financeira, as empresas privadas apresentam um melhor desempenho, gerando maior valor em relação a recursos utilizados - a mão de obra no caso em questão. Tal resultado caminha em direção a estudos que apontam uma maior eficiência de gestão das empresas privadas (CHAIN; SILVA; MARTINS, 2007; PINHEIRO; GIAMBIAGI, 2004; WERNECK, 1989).

Contudo, sob um viés social, as empresas estatais abrem mão de uma maior eficiência por empregado, contribuindo para a manu- 
tenção de uma maior taxa de emprego - o que vai ao encontro dos anseios do cidadão comum (EXAME, 2008) - e, por consequência, agindo, preventivamente, contra o recrudescimento do processo de concentração de renda no país. Cabe ressaltar, contudo, que não há consenso quanto a esse posicionamento (CASTELAR, 2001).

As diferenças percebidas entre os dois grupos de empresas sintetizam o desafio enfrentado pelas empresas na sociedade capitalista atual. De um lado há uma pressão por parte dos acionistas para uma maior eficiência na gestão, que resulte em maior distribui- ção de dividendos e investimento constante que assegure a continuidade das operações. De outro, tem-se o impacto das atividades empresariais em indicadores sociais como distribuição de renda e manutenção da taxa de emprego. Essas diferenças apontadas apresentam questões que devem ser consideradas na perspectiva de serem examinados os processos de privatização. As questões políticas relacionadas à questão demonstram outros interesses do Estado nas empresas por ele geridas, sob a ênfase social, ou seja, notadamente, a busca pela manutenção do emprego é uma delas.

\section{Referências}

ANEEL. Institui o manual de contabilidade do serviço público de energia elétrica, englobando o plano de contas revisado, com instruções contábeis e roteiro para elaboração e divulgação de informações econômicas financeiras. Resolução n. 444, de 26 de abril de 2001. Legislação federal e marginalia. Disponível em: <http:// www.aneel.gov.br $>$. Acesso em: 01 jul. 2008a. Manual de contabilidade do serviço público de energia elétrica - 2007. Disponível em: <http://www. aneel.gov.br/aplicações/leitura_arquivos/arquivos/ Manual-jan-2007.pdf $>$. Acesso em: 18 jul. 2008b. ARRIGONI, F. J. Disclosure das aplicações sociais da sociedade cooperativa e sua contribuição à elaboração do balanço social. 2000. Dissertação (Mestrado em Ciências Contábeis) - Programa de Pós-Graduação em Ciências Contábeis, Departamento de Contabilidade e Atuária, Faculdade de Economia, Administração e Contabilidade da Universidade de São Paulo, São Paulo.

BAER, W. A economia brasileira. São Paulo: Nobel, 2003. BARBOSA, R. Privatização à brasileira. Correio Braziliense, Brasília, p. 1-21, 29 jul. 1997.

BIONDI, A. O Brasil privatizado: um balanço do desmonte do Estado. São Paulo: Fundação Perseu Abramo, 1999.

BNDES, Conselho de administração, Privatização. São Paulo, 2008. Relatório. Disponível em: <http://www. bndes.gov.br $>$. Acesso em: 10 jul. 2008.

BOARDMAN, A. E.; VINING, A. R. Ownership and performance in competitive environments: a comparison of the performance of private, mixed, and state-owned enterprises. Journal of Law \& Economics, Londres, v. 32, n. 1, p. 1-33, 1989.

BOYCKO, M.; SHLEIFER, A.; VISHNY, R. W. A theory of privatization. The Economic Journal, Londres, v. 106, n. 435, p. 309-319, 1996.

BRASIL, Lei n. 11.638, de 28 de dezembro de 2007. Altera e revoga dispositivos da Lei no 6.404, de 15 de dezembro de 1976, e da Lei no 6.385, de 7 de dezembro de 1976, e estende às sociedades de grande porte disposições relativas à elaboração e divulgação de demonstrações financeiras. República Federativa do Brasil. Disponível em: <http://www.leidireito.com.br>. Acesso em: 01 jul. 2008.

BURCHELL, S.; CLUBB, C.; HOPWOOD, A. Accounting in its context: towards a history of value added in the United Kingdom. Accounting, Organizations and Society, London, v. 10, n. 4, p. 381-413, mar./apr. 1985. CARROLL, A. B. A three-dimensional concepttual model of corporate performance. Academy of Management Review, v. 4, p. 497-505, 1979.

CASTELAR, A. Economia e desenvolvimento para os novos tempos. Revista Rumos, Rio de Janeiro, ano 26, n. 181, fev. 2001.

CERTO, S. C.; PETER, J. P. Administração estratégica: planejamento e implantação da estratégia. Tradução: Flávio Deni Steffen. São Paulo: Makron Books, 1993. CHAN, B. L.; SILVA, F. L.; MARTINS, G. A. Destinação de riquezas aos acionistas e aos empregados: comparação entre empresas estatais e privadas. Revista de

Administração Contemporânea, Curitiba, v. 11, n. 4, p. 199-218, out./dez. 2007.

CHEN, H. The institutional transition of China's township and village enterprises: Aldershot: Ashgate Publishing, Brookfield, VT. 2000.

CLARKSON, M. B. E. A stakeholder framework for analyzing and evaluating corporate social performance. Academy of Management Review, v. 20, n. 1, p. 92-117, jan. 1995.

CPC - COMITÊ DE PROCEDIMENTOS CONTÁBEIS. Pronunciamento Técnico CPC 09. Disponível em: <http:// www.cpc.org.br $>$. Acesso em: 12 ago. 2008. CONSENZA, J. P. A eficácia informativa da demonstração do valor adicionado. Revista Contabilidade \& Finanças - USP, São Paulo, Edição Comemorativa, p. 7-29, out. 2003.

DEEGAN, C.; RANKIN, M.; VOGHT, P. 'Firms' 
disclosure reactions to major social incidents: Australian evidence. Accounting Forum, v. 24, n. 1, p. 101-130, 2000. DE LUCA, M. M. M. Demonstração do valor adicionado: do cálculo da riqueza criada pela empresa ao valor do PIB. São Paulo: Atlas, 1998.

EXAME. Questões vitais sobre o crescimento. Disponível em: <http://portalexame.abril.uol.com.br/revista/exame/ edicoes/0839/negocios/m0040657.html> . Acesso em: 16 jun. 2008.

FURNAS. Divisão de estudos econômicos e de mercado. Informativo gerencial mercado e economia. Brasília, 2008. Relatório. Disponível em: <http://www.furnas.com.br >. Acesso em: 01 jul. 2008.

GIAMBIAGI, F.; ALEM, A. Finanças públicas, teoria e prática no Brasil. Rio de Janeiro: Campus, 1999.

ISENMANN, R.; BEY, C.; WELTER, M. Online reporting for sustainability issues. Business Strategy and the EnvIronment, v. 16, n. 7, p. 487-501, 2007.

IUDÍCIBUS, S.; MARTINS, E.; GELBCKE, E. R. Manual de contabilidade das sociedades por ações: aplicável às demais sociedades. São Paulo: Atlas, 2003.

JENSEN, M. C.; MECKLING, W. H. Theory of the firm: managerial behavior, agency costs and ownership structure. Journal of Financial Economics, Londres, v. 3, n. 4, p. $305-360,1976$.

KARAMANIS, K. Managing privatizations in the telecommunications sector. Strategic Change, v. 18, p. 81-91, 2009.

MARTINS, G. A. Estatística geral e aplicada. São Paulo: Atlas, 2001.

MATOS, H. A imagem pública do empresariado nacional no debate sobre a privatização brasileira: 1985-1998. In: CONGRESSO BRASILEIRO DA COMUNICAÇÃO, 24., 2001, Campo Grande, set. 2001.

NETO, S. L. Privatizações e suas conseqüências políticas e econômicas, um estudo preliminar. In: ENCONTRO DA ASSOCIAÇÃO BRASILEIRA DE CIÊNCIA POLÍTICA, 3., 2002, Niterói. Disponível em: <http://www.

cienciapolitica.org.br/encontro/poleco.htm>. Acesso em: 30 jun. 2008.

OLIVEIRA, P. H. D.; LUSTOSA, P. R. B. Custos primários como parâmetro de eficiência produtiva: uma análise empírica da Companhia Vale do Rio Doce antes e após a privatização. In: CONGRESSO USP DE CONTROLADORIA E CONTABILIDADE, 5., 2005, São Paulo. Anais... São Paulo: FEA/USP, 2005.

CD-ROM.

PEROTTONI, M. A.; CUNHA, A. S. Balanço social.

Revista Brasileira de Contabilidade, v. 26, n. 104, p. 12-20, mar./abr. 1997.

PINHEIRO, A. C. Impactos microeconômicos da privatização no Brasil. Pesquisa e planejamento. econômico, São Paulo, v. 3, n. 26, p. 357-397, 1996. ; GIAMBIAGI, F. As empresas estatais e o programa de privatização do governo Collor. Pesquisa e Planejamento Econômico, São Paulo, v. 22, n. 2, p. 241288, 2004

POCHAMANN, M. A década dos mitos: o novo modelo econômico e a crise do trabalho no Brasil. São Paulo: Contexto, 2001.

RIOLI, V. Balanço social. Folha de São Paulo, p. 2-2, 16 jul. 1997:

SANTOS, A. Demonstração do valor adicionado: como elaborar e analisar a DVA. São Paulo: Atlas, 2003.

SOUZA, H. Empresa pública e cidadã. Folha de São Paulo, p. 2-2, 26 mar. 1997.

SUCUPIRA, J. A responsabilidade social das empresas. Disponível em: <http://www.balancosocial.org.br >. Acesso em: 25 jun. 2008.

TINOCO, J. E. P. Balanço social: uma abordagem da transparência e da responsabilidade pública das organizações. São Paulo: Atlas, 2001

TREBECK, K. Exploring the responsiveness of companies: corporate social responsibility to stakeholders. Social Responsibility Journal, v. 4, n. 3, p. 349-365, 2008.

WANG, X. Analyzing work attitudes of Chinese employees: a comparison between state-owned and privately-owned enterprises in China. Chinese Management Studies, v. 2, n. 3, p. 215-228, 2008. WERNECK, R. L. F. Aspectos macroeconômicos da privatização no Brasil. Pesquisa e Planejamento Econômico, São Paulo, v. 19, n. 2, p. 277-307, 1989. WRIGHT, P.; KROLL, M. J.; PARNELL, J. Administração estratégia: conceitos. Tradução: Celso Rimoli; Lenita R. Esteves. São Paulo: Atlas, 2000. 